\title{
SURTO DE TOXOPLASMOSE AGUDA TRANSMITIDA ATRAVÉS DA INGESTÃO DE CARNE CRUA DE GADO OVINO
}

\author{
Ana Maria Bonametti, Joselina do Nascimento Passos, \\ Edina Mariko Koga da Silva e André Luiz Bortoliero
}

\begin{abstract}
Os autores apresentam 17 casos de toxoplasmose aguda sintomática adquirida pela ingestão de carne crua de carneiro, servida em uma festa à qual todos os pacientes compareceram. Em relação ao quadro clínico, o período de incubação da doença variou de 6 a 13 dias (10,9 7,0) e 16 (94,5\%) pacientes apresentaram febre, cefaléia, mialgia, artralgia e adenomegalia (cervical ou cervical/axilar). Outros sinais clinicos encontrados foram: hepatomegalia em 6 pacientes, esplenomegalia em 4 e exantema em 2. Um paciente apresentou quadro clínico de corioretinite, confirmada através de exame oftalmológico. Todos os pacientes apresentavam títulos séricos de anticorpos específicos (IgG e IgM) que evidenciavam fase aguda de toxoplasmose, pela Reação de Imunofluorescência Indireta. Todos os pacientes foram tratados especificamente $e$ houve boa resposta clinica e laboratorial ao tratamento.

Palavras-chaves: Toxoplasma gondii. Toxoplasmose. Transmissão. Ovinos.
\end{abstract}

A toxoplasmose é uma infecção causada pelo Toxoplasma gondii, protozoário intracelular obrigatório, de distribuição cosmopolita ${ }^{22}$. O gato é o hospedeiro definitivo, enquanto o homem, outros mamíferos e as aves são hospedeiros intermediários ${ }^{9022}$.

Embora seja possível que o ciclo do T. gondii possa ser perpetuado na ausência de felinos, parece que esses animais são de importância primária na transmissão da toxoplasmose na maioria das regiões do mundo ${ }^{6911}$. Ainda que o gato se constitua no único hospedeiro urbano completo, outros felídeos silvestres também são capazes de eliminar formas infectantes do protozóario através das fezes, mantendo o ciclo epidemiológico em áreas não urbanizadas ${ }^{8}$.

A maioria das infecções é assintomática, sendo a doença uma exceção no homem ${ }^{13}$. Vários inquéritos realizados no Brasil em populações urbanas e rurais e inclusive em indígenas têm demonstrado a prevalência de sororeagentes, geralmente acima de $50 \%$ nas

Departamento de Clínica Médica da Universidade Estadual de Londrina, PR e de Pediatria da Universidade de São Paulo, São Paulo, SP.

Endereço para correspondência: Prof ${ }^{\text {a }}$ Ana Maria Bonametti. Departamento de Clínica Médica/CCS/UEL. R. Roberto Koch 60, Cervejaria, 86038-440 Londrina, PR. Fax (043) 336-0630.

Recebido para publicação em 17/01/96. amostras analisadas 5 . Em algumas regiões, 40\% a $70 \%$ dos adultos aparentemente sãos apresentam-se positivos para toxoplasmose em testes sorológicos ${ }^{10}$. Esta variação da prevalência parece ser devido a fatores geográficos, climáticos, hábitos alimentares, tipos de trabalho etc .

O hábito alimentar de consumo de carnes e produtos de origem animal, crus ou mal cozidos tem grande importância na epidemiologia da toxoplasmose ${ }^{2}$. Com o propósito de ressaltar este fato, os autores apresentam 17 casos de toxoplasmose aguda sintomática transmitida através da ingestão de carne crua de carneiro.

\section{MATERIAL E MÉTODOS}

Foram estudados 17 pacientes com quadro clínico e perfil sorológico compatível com toxoplasmose aguda. Todos os pacientes relatavam ingestão de carne crua de carneiro (quibe) servida em uma festa realizada em 13 setembro de 1993 na cidade de Bandeirantes (PR). Oito $(47,1 \%)$ dos pacientes eram do sexo masculino . A faixa etária variou de 6 a 57 anos $(34,5 \pm 10,9)$, sendo que apenas um paciente tinha menos de 10 anos de idade, 13 tinham entre 20 e 40 anos e 3 pacientes tinham mais de 40 anos. Todos os casos foram atendidos em clínica privada de doenças transmissíveis. A primeira consulta foi realizada no período de 27 de setembro a 28 de outubro de 1993. 
Bonametti AM, Passos JN, Silva EMK, Bortoliero AL. Surto de toxoplasmose aguda transmitida através da ingestão de carne crua de gado ovino. Revista da Sociedade Brasileira de Medicina Tropical 30:21-25, janfev, 1997.

Os pacientes responderam a um questionário no qual constavam dados sobre identificação, informações epidemiológicas e história clínica. Nenhum paciente relatou contato direto com gatos ou ingestão de carne crua de qualquer espécie a não ser a ingerida na festa.

O diagnóstico sorológico de toxoplasmose aguda foi estabelecido através da quantificação de anticorpos específicos (IgG e IgM) pela técnica de imunofluorescência indireta (kit comercializado pela Biolab diagnóstico) realizado pelo Laboratório Médico de Londrina (Labmed). Os valores de referência utilizados por esse laboratório na pesquisa de anticorpos específicos para infecção pelo T. gondii são:

anticorpos específicos da classe $\operatorname{IgG}=$ reagente até 4.000 .

anticorpos específicos da classe $\operatorname{IgM}=$ não reagente.

\section{RESULTADOS}

O período de incubação da doença variou de 6 a 13 dias $(10,9 \pm 7,0)$ e os sintomas e sinais observados com maior frequência na primeira consulta foram: febre, artralgia, mialgia, cefaléia e adenomegalia (cervical ou cervical/axilar) (Tabela 1); outros sinais clínicos encontrados foram: hepatomegalia em 6 pacientes, esplenomegalia em 4 e exantema em 2. Um paciente apresentou quadro clínico compatível com coriorretinite, confirmado através de exame oftamológico, que teve início em torno de 32 dias após a infecção e 20 dias após os sinais e sintomas iniciais. Dos 16 pacientes que apresentaram febre, 10 relatavam temperatura axilar superior a $39,5^{\circ} \mathrm{C}$ (Tabela 2 ). $\mathrm{Na}$ maioria dos casos $(58,8 \%)$ a febre teve duração de 6 a 9 dias (Tabela 3).

Tabela 1 - Distribuição dos pacientes segundo os sinais e sintomas presentes na primeira consulta.

\begin{tabular}{lcc}
\hline Sinais e sintomas & № & $\%$ \\
\hline Febre & 16 & 94,1 \\
Artralgia & 16 & 94,1 \\
Mialgia & 16 & 94,1 \\
Adenomegalia & 16 & 94,1 \\
Cefaléia & 16 & 94,1 \\
Hepatomegalia & 6 & 35,3 \\
Esplenomegalia & 4 & 23,5 \\
Exantema & 2 & 11,8 \\
Alteração ocular & 1 & 5,8
\end{tabular}

Os exames laboratoriais inespecíficos (leucograma e velocidade de hemosedimentação) colhidos no primeiro atendimento revelaram
VHS aumentado em 8 pacientes, leucocitose em 3 e linfocitose em 8 (Tabela 4). O diagnóstico de toxoplasmose aguda foi estabelecido pela presença de anticorpos específicos das classes IgG e IgM, através da reação de imunofluorescência indireta (Tabelas 5 e 6).

Tabela 2 - Distribuição dos pacientes de acordo com a temperatura axilar relatada na primeira consulta.

\begin{tabular}{lrr}
\hline Temperatura $\left({ }^{\circ} \mathrm{C}\right)$ & № & $\%$ \\
\hline$<37,5$ & 1 & 5,9 \\
37,5 I- I 38,5 & 0 & 0,0 \\
38,6 I- I 39,5 & 6 & 35,3 \\
$>39,5$ & 10 & 58,8 \\
\hline Total & 17 & 100,0 \\
\hline
\end{tabular}

Tabela 3 - Distribuição dos pacientes de acordo com a duração da febre.

\begin{tabular}{lrr}
\hline Duração da febre (dias) & № & $\%$ \\
\hline Indeterminada & 4 & 23,5 \\
6 ।- | 9 & 10 & 58,8 \\
10 |- | 15 & 2 & 11,8 \\
$>15$ & 1 & 5,9 \\
\hline Total & 17 & 100,0 \\
\hline
\end{tabular}

Tabela 4 - Distribuição dos pacientes segundo as alterações dos exames laboratorias inespecíficos no piimeiro atendimento.

\begin{tabular}{lrc}
\hline Alterações dos exames inespecíficos & № & $\%$ \\
\hline VHS elevado $\left(>20 \mathrm{~mm} / 1^{\mathrm{a}}\right.$ hora) & 12 & 70,5 \\
Leucocitose $\left(>10.000 / \mathrm{mm}^{3}\right)$ & 3 & 17,7 \\
Linfocitose $(>50 \%)$ & 8 & 47,0
\end{tabular}

Linfocitose $(>50 \%)$

47,0

Tabela 5 - Distribuicão dos pacientes de acordo com o título de $\operatorname{IgG}$ (Reaçâo da Imunofluorescencia Indireta) no atendimento inicial. \begin{tabular}{lcc}
\hline Título de IgG & № & $\%$ \\
\hline$\leq 1 / 1.000$ & 4 & 23,5
\end{tabular}

$1 / 4.000 \mid-1 / 8.000 \quad 5 \quad 29,4$

\begin{tabular}{l|ll}
$1 / 8.000 \mid-16.000$ & 3 & 17,7
\end{tabular}

$\begin{array}{lll}\geq 1 / 16.000 & 5 & 29,4\end{array}$

Total $17 \quad 100,0$

Tabela 6 - Distribuicão dos pacientes segundo o título de IgM (Reação da Imunofluorescência Indireta) no atendimento inicial.

\begin{tabular}{lrc}
\hline Título de IgM & № & $\%$ \\
\hline $1 / 16$ I- $1 / 32$ & 2 & 11,8 \\
$1 / 32$ | - $1 / 64$ & 7 & 41,2 \\
$\geq 1 / 64$ & 8 & 47,0 \\
\hline Total & 17 & 100,0
\end{tabular}

Os esquemas terapêuticos utilizados foram aqueles preconizados pela rotina da Enfermaria de Doenças Transmissíveis do Hospital Universitário Regional do Norte do Paraná (HURNP) da Universidade Estadual de Londrina ${ }^{1}$. 
Bonametti AM, Passos JN, Silva EMK, Bortoliero AL. Surto de toxoplasmose aguda transmitida através da ingestão de carne crua de gado ovino. Revista da Sociedade Brasileira de Medicina Tropical 30:21-25, janfev, 1997.

Em 16 casos foi introduzida terapêutica específica com a associação de sulfadiazina e pirimetamina imediatamente após a confirmação do diagnóstico.

A duração do tratamento foi de 40 dias e esses pacientes tiveram boa evolução clínica e laboratorial.

Uma paciente estava no $5^{\circ}$ mês de gestação e recebeu esquema terapêutico constituído por espiramicina e sulfadiazina/pirimetamina, de maneira alternada, até o término da gravidez.

\section{DISCUSSÃO}

A transmissão da toxoplasmose humana ocorre através de várias formas do parasito: oocistos em fezes de gato jovem infectado, ingestão de cistos presentes em carnes, ingestão de taquizó́tos encontrados no leite, na saliva através de lambedura ou perdigotos, no esperma e congenitamente ${ }^{1011}$. A literatura registra surtos de toxoplasmose transmitidos pelo contato direto com gatos, através da ingestão de água contaminada com oocistos ou através da ingestão de carnes de animais

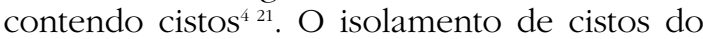
toxoplasma de carnes animais tem sido relatado por vários pesquisadores. A carne utilizada para consumo humano pode conter cistos e servir como fonte de infecção pelo $T$. gondi $i$; diferentes inquéritos revelam que mais de $25 \%$ dos carneiros e dos suínos apresentam-se infectados 23131722 . Na carne bovina o isolamento de cistos é mais raro, embora alguns autores tenham encontrado $2 \%$ a $10 \%$ de soropositividade nestes animais ${ }^{2313}$

A importância do consumo de carnes cruas ou mal cozidas ficou evidente no estudo realizado por Desmonts ${ }^{2}$, que evidenciou que crianças alimentadas com carne crua ou mal cozida de boi ou de cavalo apresentaram uma taxa de conversão sorológica cinco vezes maior do que aquela observada na população geral.

Kean e cols ${ }^{9}$ descreveram um surto de toxoplasmose aguda envolvendo cinco estudantes de medicina da Cornell University Medical College; este surto parece ter sido provocado pela ingestão de hamburger mal cozido. Em relação a estudos brasileiros, Magaldi e cols $^{215}$ relataram dois surtos de toxoplasmose aguda no Estado de São Paulo. Um ocorreu na cidade de Bragança Paulista entre estudantes de um seminário religioso, o outro surto foi detectado entre estudantes de um estabelecimento de ensino superior em São José dos Campos. O mecanismo de transmissão responsável por esses dois surtos parece ter sido a ingestão de alimentos contendo cistos do T. gondii.

Somente $10 \%$ a $20 \%$ dos casos de infecção pelo $T$. gondii no adulto são sintomáticos ${ }^{3}$. Embora o T. gondii sofra ampla disseminação durante a fase aguda da infecção adquirida, a manifestação clínica mais comum da infecção é a linfadenopatia assintomática, geralmente na região cervical, embora outros grupos de gânglios possam estar aumentados ${ }^{13}{ }^{14}$. Desde a descrição da forma linfadenopática da toxoplasmose no início dos anos 50 por Siim, Gard e Magnusson, esta forma de infecção é reconhecida como a manifestação clínica mais comum de toxoplasmose no homem ${ }^{18}$. Estimase que em torno de 15\% das linfadenopatias sem causa determinada sejam decorrentes de toxoplasmose aguda ${ }^{12}$.

Febre, mal estar, sudorese noturna, mialgia, exantema maculopapular e atipia linfocitária $(<10 \%)$ também podem fazer parte do quadro clínico da toxoplasmose aguda ${ }^{3691320}$.

De forma semelhante ao relatado na literatura, as manifestações clínicas mais frequentes apresentada neste estudo foram: linfadenopatia cervical ou cervical/axilar, febre, cefaléia, mialgia e artralgia. Todos os pacientes compareceram à mesma festa onde ingeriram carne crua de carneiro servida sob a forma de quibe.

Em relação às alterações laboratoriais inespecíficas, observou-se linfocitose em $47 \%$ dos casos e VHS elevado em 70,5\%.

Apesar de todos os pacientes apresentarem resultado sorológico compatível com Perfil I (infecção recente pelo T. gondii), segundo valores referenciais fornecidos pelo laboratório onde foram realizadas as sorologias, chama nossa atenção os baixos níveis de IgM apresentados pelos pacientes. Nove $(53,0 \%)$ apresentavam títulos de IgM menores que $1 / 64$. Segundo Remington e cols ${ }^{19}$, um título $\geq 1 / 160$ pode ser considerado como diagnóstico de infecção aguda, porém títulos menores não eliminam a possibilidade de infecção ativa. Ainda segundo esses autores, existe uma grande variação na sensibilidade do teste de imunofluorescência indireta dependendo do laboratório. Uma baixa sensibilidade do teste parece ser a explicação 
Bonametti AM, Passos JN, Silva EMK, Bortoliero AL. Surto de toxoplasmose aguda transmitida através da ingestão de carne crua de gado ovino. Revista da Sociedade Brasileira de Medicina Tropical 30:21-25, janfev, 1997.

para os baixos títulos de anticorpos detectados nos 17 pacientes.

Foi realizado estudo sorológico (reação da imunofluorescência indireta) de 58 ovinos (100\% do rebanho da propriedade de origem da carne consumida). Títulos maiores ou iguais a 1/64 foram detectados em 24 animais, com uma prevalência de soropositividade 23,10\%, sugerindo que a carne crua desses animais pode ter sido a responsável pela transmissão da toxoplasmose aos comensais ${ }^{16}$.

$\mathrm{Na}$ profilaxia desta doença é necessário que, além do controle dos felíneos, os produtos cárneos sejam ingeridos somente quando bem cozidos ou salgados.

\section{SUMMARY}

The authors present 17 cases of symptomatic acute toxoplasmosis acquired by the ingestion of raw mutton offered during a party in September 1993. The incubation period carried from 6 to 13 days (10.9 \pm 7.0). Sixteen (94.5\%) patients presented fever, beadache, myalgia, arthralgia, and adenopathy (cervical or cervical/axilar). Hepatomegaly was found in 6 patients, splenomegaly in 4 and rash in 2. One patient presented clinical picture of chorioretinitis confirmed by ophthalmological exam. All patients showed increased serum levels of specific antibodies (IgG and IgM) on indirect immunofuorescence assay evidencing acute phase of toxoplasmosis. The patients were treated with specific drugs for toxoplasmosis and presented satisfactory clinical and laboratory response.

Key-words: Toxoplasma gondii. Toxoplamosis. Transmission. Sheeps.

\section{REFERÊNCIAS BIBLIOGRÁFICAS}

1. Baldy JL, Passos JN, Takata PK, Jabur A, Bonametti AM, de Pauli DS, Guimarães JC, Anzai ET, Elisbão MC, Bortoliero AL. Da AIDS à Varicela. Rotinas médicas para atendimento de pacientes hospitalizados com Doenças Transmissíveis. 1nd edition, Editora Roca Ltda, São Paulo, p. 106-107, 1994.

2. Baruzzi RG. Toxoplasmose: história natural e níveis de prevenção. ARS CURANDI, 9:6-22, 1976.

3. Beaman RT, McCabe RE, Remington JS. Toxoplasma gondii. In: Mandell GL, Douglas ER, Bennett JE (eds). Principles and practice of Infectious diseases. 4nd edition, Churchill Livengstone, New York, p. 2455-2475, 1995.
4. Benenson MW, Takafuji ET, Lemon SM, Greenup RL, Sulzer AJ. Oocyst-transmitted toxoplasmosis associated with ingestion of contaminated water. The New England Journal of Medicine 307: 666669, 1982.

5. Coutinho SG, Souza WJ, Coura C, Marzochi MCA, Amendoeira MR. Levantamento dos resultados das reações de imunofluorescência indireta para toxoplasmose em 6.079 pacientes de ambulatório ou gestantes no Rio de Janeiro realizadas durante os anos de 1971 a 1977. Revista do Instituto de Medicina Tropical de São Paulo 23: 48-56, 1981.

6. Feldman HA.Toxoplasmosis: an overview. Bulletin of the New York Academy of Medicine 50:110126, 1974 .

7. Feldman HA. Epidemiology of Toxoplasma Infections. Epidemiology Reviews 4:204-213,1982.

8. Focaccia R, Hyakutable S, Siciliano SF, Bazone JRC, Feldman C, Mazza CC, Veronesi R. Prevalência de Toxoplasmose-infecção em comunidades ilhadas do Litoral Sul do Estado de São Paulo. Revista do Hospital das Clínicas/Faculdade de Medicina, Universidade de São Paulo 37:164-166,1982.

9. Frenkel Jk. Toxoplasmose. In: Veronesi R (ed). Doenças Infecciosa e Parasitárias. 8nd edition, Guanabara Koogan, Rio de Janeiro, p. 734-749, 1991.

10. Kawazoe U. Toxoplasma gondii. In: Neves DP, Melo AL, Genaro O, Linardi PM (eds). Parasitologia Humana, 9nd edition, Atheneu, São Paulo, p.174-187, 1995.

11. Kean BH, Kimball AC, Christenson WN. An epidemic of acute toxoplasmosis. Journal of the American Medical Association 208: 1002-1004, 1969.

12. Krick J, Remington J.Toxoplasmosis in the adult an overview. New England Journal of Medicine 298 : 550-553, 1978.

13. Luft BJ, Remington JS. Toxoplasmosis. In: Hoeprich PD, Jordan MC (eds). Infectious Diseases. 4nd edition, JB. Lippincott Company, Philadelphia p. 1199-1214, 1989.

14. Mccabe RE, Brooks RG, Dorfman RF, Remington JS. Clinical spectrum in 107 cases of toxoplasmic lymphadenopaty. Reviews of Infectious Diseases 9: 754-774, 1987.

15. Magaldi C, Elkis H, Pattoli D, Queiroz JC, Coscina AL, Ferreira JM. Surto de toxoplasmose em um seminário de Bragança Paulista (Estado de São Paulo). Aspectos clínicos, sorológicos e epidemiológicos. Revista de Saúde 
Bonametti AM, Passos JN, Silva EMK, Bortoliero AL. Surto de toxoplasmose aguda transmitida através da ingestão de carne crua de gado ovino. Revista da Sociedade Brasileira de Medicina Tropical 30:21-25, janfev, 1997.

Pública/Faculdade de Saúde Pública, Universidade de São Paulo 1: 141-171, 1967.

16. Navarro IT, Freire RL, Passos JN. Toxoplasma gondii: animais envolvidos em surto de toxoplasmose humana na Região Norte do Paraná. Revista da Sociedade Brasileira de Medicina Tropical 27 (supl. I): 344, 1994.

17. Navarro IT, Vidotto O, Giraldi N, Freire RL. Toxoplasma gondii, isolamento em carnes e cérebro de suinos. Semina. Revista cultural e científica da Universidade Estadual de Londrina 13:10-15, 1992.

18. Remington JS.Toxoplasmosis in the adult. Bulletin of the New York Academy of Medicine 50:211224,1974 .

19. Remington JS, McLeod R, Desmonts G. Toxoplasmosis. In: Remington JS, Klein JO (eds).
Infectious Diseases of the Fetus Newborn Infant. 4nd edition, WB Saunders Company, Philadelphia, p.140-267, 1995.

20. Stagno S. Toxoplasmosis. American Journal of Nursing 80: 720-722, 1980.

21. Teutsch SM, Juranek DD, Sulzer A, Dubey JP, Sikes RK. Epidemic toxoplasmosis associated with infected cats. The New England Journal of Medicine 29: 695-699, 1979.

22. Vidotto O, Navarro IT, Giraldi N, Mitsuka R, Freire RL. Estudo epidemiológico da toxoplasmose em suínos da região de Londrina, PR. Semina. Revista cultural e científica da Universidade Estadual de Londrina, 11:53-59, 1990. 